\title{
A COMPREHENSIVE ABOUT THE PART OF SPEECH USING MIND MAPPING ATSTUDENTS OF2017A STKIP PGRI JOMBANG
}

\author{
C. Sariroh \\ STKIP PGRI Jombang \\ chilyatus2015@gmail.com \\ F. Safitri \\ STKIP PGRI Jombang \\ fds0497@gmail.com \\ M. Putri \\ STKIP PGRI Jombang \\ mayrosaputri05@gmail.com \\ Chalimah \\ STKIP PGRI Jombang \\ Chalimahstkipjb@gmail.com
}

\begin{abstract}
We present an implementation about mind mapping learning of part of speech on direct explanation using mind mapping to the students. This research aims to share the knowledge about learning part of speech using mind mapping and also to know the students' comprehension ability about it. So that student can understand its function of each part of speech by using simple learning of mind mapping. This study was carried out among 20 students ofSTKIP PGRI Jombang especially in English Department. This study was descriptive and applied qualitative research method. The results show that $25 \%$ student have a very good comprehension and 50\% have good comprehension $20 \%$ have an enough comprehension and the last 5\% are having low comprehension about part of speech $(n=20)$. Part of speech is one of grammar factor that very important basic to understand the whole next grammar. Therefore, we need to share the explanation clearly and simple to the students who still don't understand. In conclusion, the students' comprehension in grammar about part of speech using mind mapping were categorized into "good comprehensive" category. However, based on these results, we have managed to put forward a number of recommendation and suggestion.
\end{abstract}

Keywords : mind mapping, part of speech, grammar. 


\section{INTRODUCTION}

There exist various approaches to taking it, and the mind mapping (mental mapping, semantic mapping, concept mapping) is one of them. First, the term appeared in 1970s in the concept introduced by Buzan (2001) ${ }^{[1]}$. Tony Buzan introduced mind mapping technique to the world with his books and developed a system which would pave the way for many people. This mind mapping technique was developed toward the end of the 1960s and has been employed in many different areas since the development. Mind Maps help students remember information, as they hold it in a format that the mind finds easy to recall and quick to review. It also helps the students to improve their innovative and creative thinking. One of the most fundamental concepts of linguistics is that of word classes. In all languages, words can be grouped in distinct classes with different semantic and syntactic functions. In English the words have traditionally been classifi ed into eight classes: nouns, pronouns, adjectives, verbs, adverbs, prepositions, conjunctions, and interjections ${ }^{[3]}$. The researchers will give explanation about mind mapping of part of speech after that give the student some questionnaire to fill.

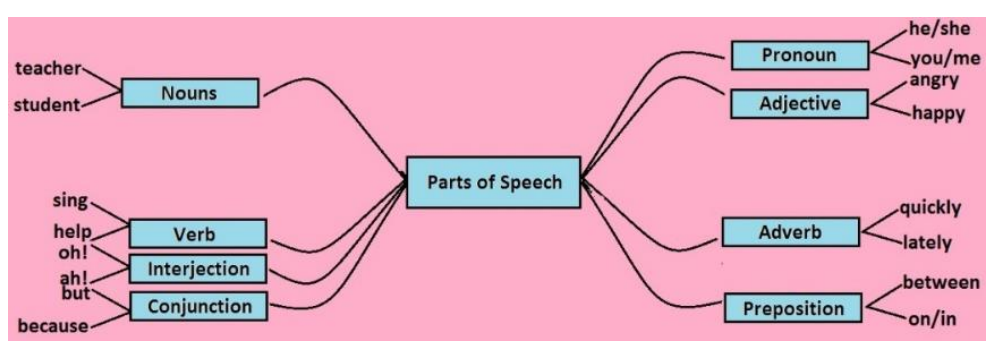

Figure 1. Example of mind mapping picture

Many students do not distinguish between adjectives and adverbs, or between adjectives and verbs, or another parts. Because of such variation in the number of categories and their identifying properties, analysis of parts of speech must be done for each individual language. Nevertheless, the labels for each category are assigned on the basis of universal criteria.this way we need to find the solution to make the student understand about part of speech.We present mind mapping learning to the student to learn part of speech easily. However, the practical application of this way is limited because of the complex solution required. $\mathrm{n}$ this research we present mind mapping to learn part of speech. so the problems of research are :

1. Is there a comprehensive about the part of speech using mind mapping at 
students of 2017A STKIP PGRI result is counted by percentage. The Jombang? percentage was counted by using this

2. Does mind mapping affect at students formula :

of 2017A of STKIP PGRI Jombang comprehension about the part of

Total of correct answer x 100 speech?

\section{METHODOLOGY OF RESEARCH}

In this study, the descriptive approach was used and applied in qualitative research methods. Through this approach, it is used to know the frequently for grammar related learning where the individual is being described in term. Since this study used a descriptive approach and its purpose was identify the degree and the frequently of a comprehensive about the part of speech using mind mapping at student of 2017A STKIP PGRI Jombang, the validity was also measured.

The first questionnaire was preliminary designed with a total of (10) statements used a likert scale with five options (Strongly Agree, Agree, Don't know, Disagree and Strongly Disagree) that counted by SPSS. after the members anwering the questionnaire we applied them on percentage.The second questionnaire also was designed with a total of (10) multiple choices and the 


\begin{tabular}{|c|c|c|c|c|c|}
\hline Statement & $\mathbf{S A}$ & $\mathbf{A}$ & DK & SD & $\mathbf{D}$ \\
\hline $\begin{array}{l}\text { 1. The definition "A noun is a person, place, thing or } \\
\text { idea" is accurate }\end{array}$ & $45 \%$ & $5 \%$ & $0 \%$ & $0 \%$ & $5 \%$ \\
\hline $\begin{array}{l}\text { 2. The definition "A noun is a person, place, thing or } \\
\text { idea" is useful even if it isn't } 100 \% \text { accurate }\end{array}$ & $20 \%$ & $45 \%$ & $5 \%$ & $5 \%$ & $25 \%$ \\
\hline $\begin{array}{l}\text { 3. The definition "A verb is an action word or a } \\
\text { state of being word" is accurate }\end{array}$ & $40 \%$ & $50 \%$ & $10 \%$ & $0 \%$ & $0 \%$ \\
\hline $\begin{array}{l}\text { 4. The definition "An adjective modifies or decribes } \\
\text { a noun or pronoun" is accurate. }\end{array}$ & $50 \%$ & $40 \%$ & $10 \%$ & $0 \%$ & $0 \%$ \\
\hline 5. A pronoun replaces a noun. & $60 \%$ & $30 \%$ & $5 \%$ & $0 \%$ & $5 \%$ \\
\hline 6. Conjunction is different from preposition & $55 \%$ & $35 \%$ & $5 \%$ & $0 \%$ & $5 \%$ \\
\hline 7. Verb and adverb is different & $65 \%$ & $30 \%$ & $0 \%$ & $5 \%$ & $0 \%$ \\
\hline $\begin{array}{l}\text { 8. The definition "adverb describes a verb an } \\
\text { adjective, or another adverb " is accurate }\end{array}$ & $35 \%$ & $10 \%$ & $50 \%$ & $5 \%$ & $0 \%$ \\
\hline 9. There are eight parts of speech in English & $65 \%$ & $30 \%$ & $5 \%$ & $0 \%$ & $0 \%$ \\
\hline $\begin{array}{l}\text { 10. I can understand and describe the parts of speech } \\
\text { in a sentence }\end{array}$ & $5 \%$ & $75 \%$ & $0 \%$ & $10 \%$ & $10 \%$ \\
\hline
\end{tabular}

Table 1. degree according scale likert about a comprehensive about the part of speech using mind mapping at student of 2017A STKIP PGRI Jombang

SA :Strongly Agree

A : Agree

DK : Don't Know

SD : Strongly Disagree

D : Disagree

Table 5 above shows the result of each statement's percentage. The statement number (1) shows that students mostly know about what noun is. The statement number (2) shows the degree is medium still related to the statement before. The statement number (3) and (4) also shows medium comprehension about verb and asjective. Then the statement number (5) and (6) they mostly understand about pronoun, conjunction and preposition. Just a few student that confused to differentiate them. The statement number (7) result also not far different from the previous statement result. The statement number (8) mostly of student still don't know about adverb. And this need to learn deeply again. The statement number (9) mostly of them agree about the eight of part of speech. and the last statement (10) mostly of them have medium degree to understand and describe the part of speech in a sentence. 
The second questionnaire also was designed with a total of (10) multiple choices and the result is counted by percentage. After analizing the data by classifying it, the findings are counted to find out the frequency, percentage, and the most frequent kinds of studends comprehension. The data analysis shows four categories of students comprehension. There are student have (1) a very good comprehension, good comprehension, enough comprehension, and(4) having low comprehension about part of speech.

\begin{tabular}{clcc}
\hline No. & $\begin{array}{l}\text { Kind of student } \\
\text { comprehension }\end{array}$ & Frequencies & precentage \\
\hline 1 & $\begin{array}{l}\text { Very good } \\
\text { comprehension }\end{array}$ & 5 & $25 \%$ \\
\hline 2 & $\begin{array}{l}\text { Good } \\
\text { comperehension }\end{array}$ & 10 & $50 \%$ \\
\hline 3 & $\begin{array}{l}\text { Enough } \\
\text { comprehension }\end{array}$ & 4 & $20 \%$ \\
\hline 4 & $\begin{array}{l}\text { Low } \\
\text { comprehension }\end{array}$ & 1 & $5 \%$ \\
\hline & Total & 20 & $100 \%$ \\
\hline
\end{tabular}

Table 2. the degree according classified the kind of student comprehension and frequencies to know a comprehensive about the part of speech using mind mapping at student of 2017A STKIP PGRI Jombang
This last questionnaire is concluded the previous questionnaire. And it shows the average of all student comprehension based of the questions about decide what kind of part of speech are in each sentence. So, the researchers take the this results as the main point of all result.

\section{CONCLUSION}

The results show that $25 \%$ student have a very good comprehension and 50\% have good comprehension $20 \%$ have an enough comprehension and the last 5\% are having low comprehension about part of speech $(n=20)$. So, mind mapping as easy way to learn parts of speech in grammar was satisfactory good. And there is no doubt about mind mapping explanation to applied in part of speech material. But for the student who has low comprehension they need to learn again about it in the same way or it can be learnt in another way intensifely. 


\section{REFERENCES}

Simonova, Ivana (2013). Concept of ELearning Reflected in Mind Maps of University Students. University of Hradec Králové, Rokitanského 62, Hradec Králové, 500 03, Czech Republic
T. K. Tee, M. N. A. Azman, S. Mohamed, Muhammad, M., M. M. Mohamad, J. Md Yunos, M. H. Yee, W. Othman (2014). Buzan Mind Mapping: An Efficient Technique for NoteTaking

Gärdenfors, Peter (2014). A Semantic Theory of Word Classes. 


\section{Appendix}

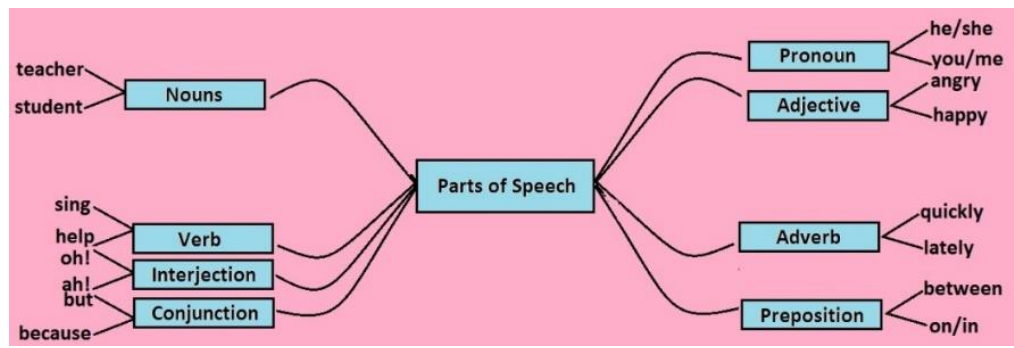

Name:

Class:

Directions: Circle the one letter (SA, A, DK, SD, D) that most closely fits your answer to each statement.

SA (Strongly Agree): You are absolutely sure about the accuracy/truth of the statement.

A (Agree): You are fairly confident about the accuracy/truth of the statement/

DK (Don't Know): You don't have an opinion about the statement partly because you don't know the terms used.

D (Disagree): You believe the statement is inaccurate/wrong.

SD (Strongly Disagree): You know for sure that the statement is wrong/inaccurate..

\begin{tabular}{|c|c|}
\hline The definition "A noun is a person, place, thing or idea" is accurate & SA A DK SD D \\
\hline $\begin{array}{l}\text { 2. The definition "A noun is a person, place, thing or idea" is useful even if it isn't } \\
100 \% \text { accurate }\end{array}$ & SA A DK SD D \\
\hline 3. The definition "A verb is an action word or a state of being word" is accurate & SA A DK SD D \\
\hline 4. The definition "An adjective modifies or decribes a noun or pronoun" is accurate. & SA A DK SD D \\
\hline A pronoun replaces a noun. & SA A DK SD D \\
\hline Conjunction is different from preposition & SA A DK SD D \\
\hline Verb and adverb is different & SA A DK SD D \\
\hline The definition "adverb describes a verb an adjective, or another adverb " is & SA A DK SD D \\
\hline There are eight parts of speech in English & SA A DK SD D \\
\hline I can understand and describe the parts of speech in a sentence & SA A DK SD D \\
\hline
\end{tabular}


Sariroh dan Safitri,, A Comprehensive...

(Direction: circle the correct answer below)

\section{Questions}

1. Do you want to come to the playground with us?

A. Noun

B. Verb

C. Adjective

D. Adverb

2. Mandy was so happy she skipped down the street.

A. Noun

B. Verb

C. Adjective

D. Adverb

3. We hung shiny decoration on our Chritmas tree.

A. Noun

B. Verb

C. Adjective

D. Adverb

4. Carlos can run faster than anyone in our school

A. Noun

B. Verb

C. Adjective

D. Adverb

5. please get me a bunch of ripe bananas when you go to the store

A. Noun

B. Verb

C. Adejective

D. Adverb

6. Jalen's dad sings loudly in the shower.

A. Noun

B. Verb

C. Adjective

D. Adverb

7. Alex choked on his food because he ate so fast.

A. Noun

B. Verb

C. Adjective

D. Adverb

8. Did you finish your homework yet?

A. Noun

B. Verb

C. Adjective

D. Adverb

9. we're having pizza for dinner tonight.

A. Noun

B. Adverb

C. Adjective

D. Adverb

10. Emily has to clean her messy room before she goes out.

A. Noun

B. Verb

C. Adjective

D. Adverb
Results of second questionnaire

\begin{tabular}{ll}
\hline Respondent & Score \\
\hline Respondent 1 & $100 / 100$ \\
\hline Respondent 2 & $70 / 100$ \\
\hline Respondent 3 & $90 / 100$ \\
\hline Respondent 4 & $100 / 100$ \\
\hline Respondent 5 & $100 / 100$ \\
\hline Respondent 6 & $30 / 100$ \\
\hline Respondent 7 & $70 / 100$ \\
\hline Respondent 8 & $70 / 100$ \\
\hline Respondent 9 & $90 / 100$ \\
\hline Respondent 10 & $70 / 100$ \\
\hline Respondent 11 & $100 / 100$ \\
\hline Respondent 12 & $90 / 100$ \\
\hline Respondent 13 & $90 / 100$ \\
\hline Respondent 14 & $90 / 100$ \\
\hline Respondent 15 & $100 / 100$ \\
\hline Respondent 16 & $90 / 100$ \\
\hline Respondent 17 & $90 / 100$ \\
\hline Respondent 18 & $90 / 100$ \\
\hline Respondent 19 & $90 / 100$ \\
\hline Respondent 20 & $90 / 100$ \\
\hline
\end{tabular}

Score $100=25 \%$

Score $90=50 \%$

Score $70=20 \%$

Score $30=5 \%$ 